\title{
The Effects of Career Choice Guidance on Identity Development
}

\author{
E. Saskia Kunnen \\ Department of Developmental Psychology, University of Groningen, Grote Kruisstraat 2/1, 9712 TS Groningen, The Netherlands
}

Correspondence should be addressed to E. Saskia Kunnen; e.s.kunnen@rug.nl

Received 10 December 2012; Revised 7 March 2013; Accepted 7 March 2013

Academic Editor: Eric Z. F. Liu

Copyright (C) 2013 E. Saskia Kunnen. This is an open access article distributed under the Creative Commons Attribution License, which permits unrestricted use, distribution, and reproduction in any medium, provided the original work is properly cited.

\begin{abstract}
We investigated the effects of a student career choice guidance on identity development. We compared the levels of identity development before and after the guidance. In addition we compared the identity development of the participants with a norm group of the same age and educational level. Following the guidance we found-as expected-that the participants showed a significant increase in commitment strength in the vocational and personal domains and in global identity. The effect size was moderate. The participants showed significantly higher increase levels than did the norm group. The initial commitment strength in the group with career choice problems was lower as compared to the norm group in the vocational and personal domain but not in the global identity.
\end{abstract}

\section{Introduction}

In this paper we discuss the effects of a career guidance program on the identity development of students with career choice problems. Starting from the perspective of identity theory, we argue that career choice intervention in late adolescents should not only address the commitment formation in the vocational domain, but also in the personal and global domain.

Career choice is seen as one of the major tasks in late adolescents' identity development. In Erikson's life-span stage theory, identity development is the main developmental task in late adolescence [1]. Exploration and commitment formation are seen as two crucial dimensions in identity development [2]. By exploration we mean that individuals are seriously considering different possibilities before they form commitments. Commitment formation means making choices about what really matters to them, and in which they are personally involved. School and career are the most important domains in which commitments have to be chosen [3,4] and in order to study career choice as part of identity development, knowledge is needed about the developmental pathway of commitment formation. Kunnen et al. [5] describe the shape of individual trajectories of commitment strength and exploration. Identity development starts from a condition that is characterized by low levels of exploration. The commitment strength can be either low or high, depending on whether commitments are absent, or have been adopted from others, such as the parents, but in either situation, there is no questioning and no need to explore and develop their own commitments.

The start of development is triggered by some challenge or conflict [6]. Commitment development is a complex dynamic process that takes place in interaction between the individual and contextual demands. Either existing (adopted) commitments do not fit any longer with the demands of everyday life or the absence of commitments is felt as a problem [7]. As a consequence, levels of exploration rise, and, in case of adopted commitments, the commitment strength decreases and becomes low. In this moratorium condition [2] the individual is exploring different alternatives, searching, trying, thinking, experimenting, talking with people, and so forth. After such a period of crisis [1] the optimal outcome of identity development is that the period of exploration results in the choice of personally relevant commitments.

In case of career commitments, such commitments consist of a fit between the study or career that is chosen and personal values, skills, and preferences. This means that a vocational commitment in its optimal form is not just a choice that is felt as attractive at the moment, but it includes knowledge about who one is and wants to be, thus it requires the development of personal commitments. 
As a consequence, career choice interventions should not just address the vocational domain, but also the personal domain and global identity.

The conflicts that trigger identity development may be either internal or external. Commitments are at least partly shaped by the context. Because commitments refer to a relation between the individual and the context, contextual changes may demand new commitments and thus trigger transitions in identity. During the whole lifespan many transitions are initiated by contextual change in the form of normative societal demands $[7,8]$. In particular in adolescence and emerging adulthood, people are confronted with both individual changes and new environmental demands that force them to make decisions concerning their future occupational life $[9,10]$. As described by Arnett, the development of commitments is more and more postponed from late adolescence until emerging adulthood [9]. However, depending on the educational system of the country they live in, many youngsters have to make choices with regard to their studies and their future career already during their late adolescence. For Dutch adolescents, the most challenging domain of identity development is probably the domain of career choice. The Dutch society offers a strict structure in which adolescents, after finishing their secondary school, have to rather specific form of further education. The different forms of tertiary education (vocational training or university) are more specified than, for example, in the USA. Students choose for a major, such as psychology or chemistry, and their curriculum is focused on that specific subject. Thus, if a psychology student decides after one year that he prefers to study sociology, he has to change his studies and start again in the first year of sociology. Depending on the secondary school level adolescents face this choice somewhere between age 16 and 18. Much identity work starts around this age, and therefore we assume that for late adolescents who start identity development relatively late, the timing of this forced choice might be too early, in that they have not proceeded far enough in their identity development to make a good choice. Indeed, making the right choice turns out to be a hard task: too hard for a substantial amount of students. Figures for dropout in higher education show that about $30 \%$ of all students stop the study in the first year, mostly because the students feel they have made the wrong choice. Most of them make a new choice, but a minority does not return to school [11]. Moreover, due to increasing college fees after four year bachelor studies, changing studies and "losing" one or more years create for most Dutch students a major financial problem.

As a consequence, there is an increasing attention in The Netherlands for career choice guidance and intervention for late adolescents. There is a renewed interest in the effectiveness of several existing intensive career guidance programs, and initiatives are taken to increase the number of such intensive programs. An overview of these intensive programs is given by Stuit [12]. In this study, we will investigate the effect of one of these programs, The Saxion Orientation Traject.

A vast amount of research, especially in the United States, has demonstrated that career choice interventions can be effective $[28 ; 29 ; 30]$. In their comprehensive overview
[13] even state that career counseling is definitely found to be effective, and that we now need research that explores the potential moderating effects of clients' sex, race, sexual orientation, and so forth.

Nevertheless we think that effect evaluation of these Dutch intensive programs is relevant and informative. Firstly, it is difficult to translate the US interventions and research outcomes to The Netherlands. In addition to the differences in educational system that were discussed above, most of the programs in the USA are offered to students within the context and program of the university. The intensive programs mentioned here are offered by universities, but the participants are late adolescents who are not students at this moment. This has-among others-financial consequences: participants have to pay to participate. A more fundamental reason why our research will provide new knowledge is that we frame the question into career choice guidance explicitly in terms of identity development. That implies that we are not just interested in the effects on variables such as career certainty, indecision, and commitment to choice, but also on personal and global identity. This fits in with the argument of Montgomery et al. [14] that each intervention directed towards adolescents and emerging adults should pay attention to identity development, being the main developmental task in this stage of life. Because career choice directly concerns commitment development, this focus on identity is still more self-evident in intervention concerning career choice problems. Such intervention, or guidance, should aim to stimulate identity development and not just aim to help the participant to make a choice for a study.

We evaluate the effects of the Saxion Orientation Project, one of the programs that is analysed by Stuit [12] (The Saxion Orientation Project is a project of the Saxion University of Applied Sciences in Deventer, The Netherlands (http://www.saxion.edu/).) Stuit's overview shows that this program is rather representative for the intensive Dutch programs. For 20 years this career guidance project has offered a four-month guidance program for young people with career choice problems. The program is meant for late adolescents who seek career choice help because they either have finished secondary school and do not know what study to choose or dropped out of their studies and do not know what to do now. The participants are not students at this moment. They have to pay a fee of about 900 euro to participate. The aim of this program is not only to help the participants to make a choice, but also to help to explore themselves and to develop ideas about what is really important to them, who they are, and who they want to be. In other words, it aims to stimulate identity development. It has proven effective in that almost all participants made a career choice following the project, and $85 \%$ (against $66 \%$ in general) of the participants have kept to that choice for at least one year. The other $15 \%$ stated that they are better able to make new choices than they were before [15]. The program takes two days per week and consists of group meetings and individual sessions and homework assignments. The assignments are firstly directed towards exploring oneself, one's strong and weak points, interests, values, and so forth. In individual meetings, also individual personal problems, such as fear of failure, are addressed. 
Secondly the assignments are directed towards exploring the world: by visiting companies, schools, and universities and gathering information about different possible studies. Finally the assignments concern the ordering and selecting of the available information; they offer strategies about how to make selections and determine preferences and finally to make a choice. In the group meetings there is exchange of the results of the assignments and the experiences of the participants. The assignments and meetings concern both cognitive informational aspects and personal emotional aspects. A more detailed description of the program can be found in the appendix belonging to this paper.

Theoretically, the program can be expected to be effective [12]. Researches from different perspectives and theories distinguish different components or steps that are needed in an effective program and most of these components are present in the Saxion program. In career intervention research, five critical components for the effectiveness of career choice interventions have been distinguished [13]. Each of these components independently predicts success of the intervention. Moreover, a linear relation was found between the number of components present and the effectiveness of the intervention [13]. Four of the five components are present in the Saxion program. These are written exercises (reflection reports)-individualized interpretations and feedback (individual meetings with the counselor and discussion of reports and exercises)—world of work information, looking for brochures, and visiting information days, universities, and companies-modeling opportunities, in the form of visits to professionals.

Also studies into the effects of identity-directed interventions distinguish between different effective components [16]. These authors found that a cognitive approach to identity issues only affects the cognitive domain, and an emotional approach only affects the emotional domain. They conclude that both are necessary for an effective intervention. The Saxion program addresses both domains.

Theories on development of career choice [17-19] describe different steps in the process of career choice. Although they slightly differ, the steps in the different theories resemble each other in that they all describe a sequence of motivation, exploration, and commitment formation. Germeijs and Verschueren [17] have developed a six-step model about the way in which adolescents decide on the first step in their career choice. These different steps describe a process that starts with orientation to choice, self-exploratory behavior, broad exploratory behavior of the environment, in-depth exploratory behavior of the environment, decisional status, and commitment. All these six steps are present in the Saxion program.

Considering the literature discussed above we may assume that the Saxion program contains the components that are found to be effective in career intervention and in identity intervention. Our main research question concerns the effects of the Saxion program on vocational, personal, and global identity.

Our first hypothesis is that we find an increase in vocational, personal, and global identity commitments following the guidance program.
Our second hypothesis is based on the theoretical assumption that career choice problems in young students may be related to immature levels of identity development. We compare the identity scores of the program participants before the start with a control group of students who did make a choice. We hypothesize that the participants have lower levels of commitment than the control group, in all three domains. With regard to exploration, we expect that the participants will have lower levels of exploration in the personal and global domain but not in the vocational domain because the problems in that domain are the reason for them to enrol in the guidance, and these problems most probably trigger explorative behaviour such as thinking and talking about this problem.

Our third hypothesis is that the differences between the participants and the norm groups in commitment strength and exploration in all three domains will disappear after the guidance program.

In addition, we will compare the development in the participants group with the development in the control group. We expect that the increase in the commitment levels of the participants will be higher than those of the control group. In this way we control for the possibility that changes in identity development in the participants can be explained by normal development that is shown in all students in this age group.

Finally, we investigated the changes in exploration exploratively, because two contradictory processes are expected to occur. On the one hand, exploration may be stimulated by the guidance, resulting in an increase, while on the other hand the exploration may decrease after the participant developed a commitment and made a satisfying choice. In the latter case, a negative relation between growth of commitment strength and increase in exploration can be expected, and therefore we explored the relation between the changes in exploration and commitment within each domain separately.

\section{Method}

2.1. Participants. All 120 participants of the Career Guidance Program (Saxion Orientatieproject) in 2009, 2010, and 2011 were invited to participate in the study. About half of them agreed and participated in the preproject interviews. Of these 60 participants, 15 did not participate in the second interview session after the program. The 45 participants that participated in both interviews did not differ from the 15 dropouts with regard to the identity scores or with regard to demographic variables as age and gender. The most frequent reason for dropout was that the participants were too busy, on holidays, or at work during the time of the second interview. All participants were Dutch citizens. The age range is from age 17 to 23 . The mean age is 19 , and most participants are 18 or 19 years old. Twenty four (53\%) of the participants are women. All participants have finished the middle or highest level of Dutch secondary school. The middle educational level in The Netherlands (called HAVO) lasts 5 years and offers entrance to universities for applied sciences. The highest secondary school level (called VWO) lasts 6 years. This level gives entrance to all universities. About half the participants 
have recently finished their secondary school; the other half has started a study for at least one year and dropped out or decided after their graduation that the study did not fit their needs. Almost all participants made during or directly following the program a choice for a specific type of education program. The few who did not yet make a choice still had to decide between two options.

We compared the participants with the norm group of the GIDS [20]. This group consists of 151 students who were enrolled in university at the time of the interviews. Most of them were interviewed in the first year of their studies. The group consists of 43 male and 108 female students with a mean age of 19.1 and an age range between 17.5 and 22 years. The norm group consists of participants of three different studies. In all studies, the participants were recruited by means of announcements on university board. They were rewarded either with credits or with a small amount of money. The norm group is heterogeneous with regard to the topic of their studies. One of the groups consisted of psychology students; for other groups care was taken to include a representative sample of different studies. The scores of all three groups were highly comparably: the significance of the difference was never below $P=0.15$. The three groups were therefore combined into one norm group. A detailed description and analysis of the norm group can be found in Kunnen [20]. For some subscales different norm tables are developed for male students and for female students. Of the norm group, 93 students were interviewed a second time, with 5 months in between. The norm group matches the intervention group with regard to age mean and distribution.

2.2. Measurements. We administered an identity interview (GIDS, [3]) before and after the project. The identity interview, the Groningen Identity Development Scale (GIDS) [3], is a semistructured interview that measures the level of exploration and of commitment strength and the commitment content in different domains. It focuses on six domains: philosophy of life, parents, friendship, vocational domain, personal domain and intimate relationships, and global identity. All domains were assessed, but in this study we only use the vocational and personal domain and the global identity. The interview is administered by master students in developmental psychology, who were trained in administering the GIDS interview. For each domain, the method starts with an open interview in which the participants are stimulated to tell about themselves with regard to this domain. Next, the participants are asked to write on a card what is most important for them with regard to that particular domain. This statement is the commitment. As a next step, a questionnaire is administered about the statement on the card. This questionnaire consists of a Cscale for commitment strength (e.g.: "Do you feel involved in... (this commitment)...?") and an E-scale for exploration (e.g.: "Do you talk with others about this ... (topic)?"). The answers are rated on a 3-point scale, ranging from no/not at all (score 0 ) to somewhat or sometimes (score 1) to sure, strong, always, or yes (score 2). In this way a score is obtained per domain for exploration (range 0-28) and for commitment strength (range 0-36). Following the interviews about the six domains, the participant is asked to formulate a domain overarching commitment: the global identity. For this, the interviewer places all six cards of the different domains in front of the participant and asks whether there is something general in these different cards, something that is common, overarching. Different descriptions are used to make clear what is meant. After the participant writes down the general statement, a questionnaire is administered in the same way as for the domain-specific cards. The second identity interview was administered in the same way as the first, except that in the open interview questions were added about changes during the previous 6 months. The commitment scales in all domains had an alpha score above 0.80 . The alpha of the exploration scale in the vocational domain was 0.65 and the exploration scales of all other domains had an alpha above $0.70[21]$.

2.3. Design. The students with career choice problems were asked for participation as soon as they registered for the project. If they agreed, they were interviewed in the weeks before the start of the guidance project. About five months later, after the project was finished, a second interview was administered. The students in the control group participated either as part of their study or against payment. They were interviewed twice during their first year of study, with about 5-6 months in between both interviews.

2.4. Analysis. We started by investigating the requirements for 1-way ANCOVA, but the requirement that the error variance of the dependent variable should be equal across groups (Levene's Test of Equality of Error Variances) was not fulfilled. Therefore we had to use $t$-test analysis. To investigate the first hypothesis we analyzed the changes in the raw scores in the guidance group between the first and the second assessment by means of a $t$-test. Because these changes concern the effects of an intervention, for the domains that showed a significant increase, we also computed the effect size by means of Cohen's $d$ (the difference between both measurements divided by the average standard deviation of both measurements). To investigate the second and third hypotheses the initial commitment and exploration scores of the project participants were translated into norm scores and compared per domain with the scores of the norm group by means of a $t$-test. We used norm scores here because for some domains norms are different for male and female adolescents. The norm scores are expressed as decile scores. We compared the first measurement of the participants with the first measurement of the norm group and the second measurement of the participants with the second measurement of the norm group. To analyze whether the guidance participants showed more progress, we computed the difference scores for both the guidance group and the control group and compared these scores by means of a $t$ test. Here we used the raw scores, because we calculated the change within each individual, and information is lost when the raw scores are translated into norm scores. The changes in exploration were compared in the same way as 
TABle 1: Difference in the commitment and exploration scores per domain before (T1) and after (T2) the guidance $(n=45)$.

\begin{tabular}{|c|c|c|c|c|c|c|c|}
\hline Domain & $T 1$ & St. dev. & $T 2$ & St. dev. & $T$ & sig. (1 tailed) & Cohen's $d$ \\
\hline \multicolumn{8}{|l|}{ Commitment } \\
\hline Vocational & 22.8 & 6.72 & 26.7 & 6.31 & -3.573 & $0.003^{* *}$ & 0.60 \\
\hline Personal & 22.8 & 6.66 & 25.7 & 7.56 & -2.590 & $0.007^{* *}$ & 0.41 \\
\hline Global identity & 24.8 & 9.36 & 29.0 & 6.57 & -3.819 & $0.000^{* * *}$ & 0.52 \\
\hline \multicolumn{8}{|l|}{ Exploration } \\
\hline Vocational & 17.1 & 4.92 & 15.3 & 4.36 & 2.380 & $0.01^{* *}$ & \\
\hline Personal & 13.6 & 5.32 & 13.6 & 4.78 & 0.096 & 0.92 & \\
\hline Global identity & 12.3 & 6.00 & 11.1 & 4.91 & 2.710 & $0.01^{* *}$ & \\
\hline
\end{tabular}

${ }^{*} P<0.05 ;{ }^{* *} P<0.01 ;{ }^{* * *} P<0.001$.

TABLE 2: Commitment and exploration per domain of the participants before the start of the guidance $(n=60)$ as compared to the norm group (decile scores).

\begin{tabular}{|c|c|c|c|c|c|}
\hline & $\begin{array}{c}\text { Mean } \\
\text { norm group }\end{array}$ & $\begin{array}{c}\text { St. dev. } \\
\text { norm group }\end{array}$ & $\begin{array}{c}\text { Mean } \\
\text { participants }\end{array}$ & $\begin{array}{c}\text { St. dev } \\
\text { participants }\end{array}$ & $\begin{array}{c}\text { Significance } \\
1 \text { tailed }\end{array}$ \\
\hline \multicolumn{6}{|l|}{ Commitment } \\
\hline Vocational & 5.3 & 2.8 & 4.4 & 2.6 & $0.01^{* *}$ \\
\hline Personal & 5.3 & 2.8 & 4.3 & 2.6 & $0.01^{* *}$ \\
\hline Global identity & 5.2 & 2.7 & 4.9 & 2.7 & 0.21 \\
\hline \multicolumn{6}{|l|}{ Exploration } \\
\hline Vocational & 5.2 & 3.2 & 5.9 & 2.8 & 0.06 \\
\hline Personal & 5.3 & 2.9 & 4.5 & 2.8 & $0.04^{*}$ \\
\hline Global identity & 5.1 & 2.9 & 4.8 & 2.9 & 0.23 \\
\hline
\end{tabular}

${ }^{*} P<0.05 ;{ }^{* *} P<0.01 ;{ }^{* * *} P<0.001$.

the changes in commitment. In addition, we computed the relation between changes in commitment strength and in exploration within each domain, for both groups separately, by means of a Pearson's correlation.

\section{Results}

The commitment scores of the program participants increased significantly in the vocational and personal domain and in global identity (Table 1). We calculated Cohen's $d$ as an indication of effect size for the commitment scores that showed a significant increase, and in all cases a median effect size was found. The levels of exploration decreased significantly in the vocational domain and in the global identity.

Before the start of the guidance, the participants had-as compared to the norm group-significantly lower commitment scores in the vocational and personal domain and lower exploration scores in the personal domain. The exploration levels in the vocational domain show a tendency in the expected direction: the participants having higher scores. With regard to global identity no significant differences were found (Table 2). None of the participants' commitment or exploration scores after the program differed significantly from the scores in the norm group (Table 3 ).

As compared to the norm group the commitment scores of the guidance participants showed significantly more increase in the vocational and personal domain and in global identity. With regard to exploration, the guidance participants showed more decrease in the levels of exploration in the vocational domain and less decrease in the personal domain, as compared to the norm group. The groups did not differ in their changes in the exploration levels with regard to global identity (Table 4).

Finally, increase in commitment strength is significantly related to a decrease in exploration in the vocational and the personal domain in both groups. No significant relationship between change in commitment strength and in exploration was found in the global domain (Table 5).

\section{Discussion}

In this paper we investigated the effects of a career choice guidance on identity development. We expected and found a significant and clinically relevant increase in commitment strength in all three target domains following the program. The effect size was median, and for most aspects the increase was significant also in comparison with a norm group of the same educational level and age. This latter finding makes the explanation unlikely that the findings just reflect the normal development that can be expected at this age. These outcomes confirm the first hypothesis.

The second hypothesis could be partly confirmed: we found that compared to the norm group the initial commitment strength in the guidance group was lower in the vocational and personal domain. The initial difference with 
TABLE 3: Commitment and exploration per domain of the participants after the guidance $(n=45)$ as compared to the norm group $(n=93)$ (decile scores).

\begin{tabular}{|c|c|c|c|c|c|}
\hline & $\begin{array}{c}\text { Mean } \\
\text { norm group }\end{array}$ & $\begin{array}{c}\text { St. dev. } \\
\text { norm group }\end{array}$ & $\begin{array}{c}\text { Mean } \\
\text { participants }\end{array}$ & $\begin{array}{c}\text { St. dev } \\
\text { participants }\end{array}$ & $\begin{array}{c}\text { Significance } \\
1 \text { tailed }\end{array}$ \\
\hline \multicolumn{6}{|l|}{ Commitment } \\
\hline Study & 5.1 & 3.2 & 5.6 & 2.6 & 0.19 \\
\hline Personal & 6.0 & 3.0 & 5.8 & 3.1 & 0.34 \\
\hline Global identity & 5.6 & 2.8 & 6.4 & 2.4 & 0.07 \\
\hline \multicolumn{6}{|l|}{ Exploration } \\
\hline Vocational & 5.4 & 3.0 & 5.9 & 2.9 & 0.34 \\
\hline Personal & 4.6 & 2.7 & 4.2 & 2.8 & 0.21 \\
\hline Global identity & 4.8 & 2.7 & 4.1 & 2.8 & 0.07 \\
\hline
\end{tabular}

${ }^{*} P<0.05 ;{ }^{* *} P<0.01 ;{ }^{* * *} P<0.001$.

TABLE 4: Comparison of change in norm group and in project participants' group.

\begin{tabular}{lcccc}
\hline & $\begin{array}{c}\text { Change in } \\
\text { norm group }\end{array}$ & $\begin{array}{c}\text { Change in } \\
\text { project participants }\end{array}$ & $\begin{array}{c}\text { Significance }(P) \\
1 \text { tailed }\end{array}$ \\
\hline Commitment & & & 3.90 & $0.00^{* * *}$ \\
$\quad$ Vocational & -1.44 & 2.87 & 1.41 & 0.08 \\
Personal & 0.95 & 4.24 & 3.12 & $0.00^{* * *}$ \\
$\quad-0.48$ & & & $0.01^{* *}$ \\
Global identity & -0.02 & -1.82 & -2.32 & $0.02^{* *}$ \\
$\quad$ Exploration & -1.58 & -0.07 & 1.48 & 0.32 \\
Pecational & -0.78 & -1.16 & -2.25 & \\
Global identity & & &
\end{tabular}

${ }^{*} P<0.05 ;{ }^{* *} P<0.01 ;{ }^{* * *} P<0.001$.

TABLE 5: The correlations between change in commitment strength and exploration in the same domain $(n=45)$.

\begin{tabular}{lcccc}
\hline & Participants & Significance (2 way) & Norm group & Significance (2 way) \\
\hline Vocational & -0.45 & $0.002^{* *}$ & -0.38 & $0.000^{* * *}$ \\
Personal & -0.31 & $0.039^{*}$ & -0.24 & $0.018^{*}$ \\
Global identity & -0.06 & 0.968 & 0.024 & 0.82 \\
\hline
\end{tabular}

${ }^{*} P<0.05 ;{ }^{* *} P<0.01 ;{ }^{* * *} P<0.001$.

regard to global identity was in the expected direction but not significant. As expected, the initial level of exploration in the personal domain was significantly lower in the group of participants. The difference in exploration in global identity was in the expected direction but not significant. So, if we consider the developmental process as sketched in the introduction, the findings suggest a less mature identity profile in the participants before the start of the program.

The high exploration scores in the vocational domain can be explained by the particular situation of the guidance participants: they experienced problems in the choice of their studies to such an extent that they enroll themselves in a time- and money-consuming guidance program. Most probably, the exploration scores reflect their worries and fruitless attempts to make a satisfying choice. The exploration scale measures activities, such as thinking about their career choice, talking with other people about what to choose, and gathering information, but it does not give information concerning the effectiveness of the exploration. It may well be that the kind of exploration in the participants group is comparable to the ruminative exploration as described by Luyckx and colleagues [22]. Thus, it may be that the effect of the program on exploration is not reflected in the levels of exploration but in the quality of the exploration. Additional research into the qualitative aspects of exploration is needed to test this assumption.

The third hypothesis, that the differences between both group disappear following the intervention, can be confirmed. All significant differences in commitment strength and in exploration disappeared following the guidance program. The participant group started with lower levels of commitment strength than the control group, but they seem to catch up after the program. Exploratively we investigated 
the change in exploration scores following the program. We found a significant decrease of exploration following the program in the vocational domain and in the global identity. As discussed, two different mechanisms may affect the changes in the exploration scores. On the one hand, the program aims to stimulate and develop exploration skills. This may result in an increase in the exploration scores. On the other hand, most participants made a choice for a study during the program, and this reduces their need for exploration. Before the start of the program, the participants had significantly higher exploration scores in the domain of vocational commitments as compared to the norm group. Following the program, their vocational exploration scores were comparable to those of the norm group. This suggests that the reduced need for exploration had stronger effect on the levels of exploration than possible increase as a consequence of the increased exploration skills. The mean levels of exploration did not change in the personal domain. Contrary to the vocational domain, where the exploration process ended with a clear choice for a specific study, there is not such a clear end point with regard to the exploration of the personal domain. It seems plausible that the participants did not end the exploration of their own personal characteristics just because they made a vocational choice. The finding that in the vocational and personal domain participants who showed the most increase in commitment strength also showed the most decrease in exploration is in line with the second mechanism we mentioned above: the mechanism that the development of strong commitments reduces the need for further exploration. This seems to be a general mechanism: it is found both in the participants and in the norm group. Moreover, it is in line with other research findings [5]. The findings with regard to exploration in the global domain differ from the findings in the other domains: there was no difference between both groups at the start of the program, but following the program the participants showed significantly less exploration than the norm group (although the change between both groups did not differ significantly), and no significant relation is found between the changes in commitment and the changes in exploration. A possible explanation for this difference may be the more diffuse character of global identity. It overarches all domains, and exploration with regard to global identity is probably more diffuse and maybe even less conscious, because it is not less directed towards specific topics such as one's own career and characteristics.

The initial participants' exploration levels in the personal domain were significantly lower as compared to the norm group. Following the program these levels were comparable to the norm group, but this was mainly caused by a decrease in the exploration levels of the norm group. The decrease in exploration in the norm group was not predicted. It might be explained by a general developmental tendency in this age group. The norm group consists of students. It may be expected that university students during the first years of their studies develop commitments in different domain, and thus that the need to explore decreases in this age group. Some support for this explanation is the finding that also in the personal domain the decrease in exploration level is related to an increase in commitment strength.

The study has some limitations. Firstly, as is the case in all nonexperimental studies, we cannot be completely sure that the changes in the participants are really caused by the intervention. Statistical regression does not seem likely, because the low-scoring group (the participants) was not selected on the basis of the scores. Moreover, the difference between both groups fits in with other empirical findings. Nevertheless, we cannot rule out the possibility that other causal factors may have played a role. To know which factors may play such a role, we need more insight in the process of change during the intervention. As a first step, detailed knowledge of the developmental trajectories of commitment strength is required. This knowledge is needed to test several assumptions. Firstly, we suggested that the initially high levels of exploration in the vocational domain may reflect ineffective, ruminative exploration, and effects of the program on exploration may be more qualitative than quantitative. Detailed followup of the participants with a focus on the quality of the exploration may test that assumption. Secondly, we assumed, on a theoretical basis, that the development of mature and personal meaningful commitments takes place following a period in which much exploration takes place. Implicitly we assumed here too that a peak in exploration took place during the program and has decreased again at the time of our second measurement. To test these assumptions, we need more knowledge concerning the medium and shortterm processes of identity development during the program, thus, about the individual trajectories on a time scale of weeks and months. Recent longitudinal studies on identity development $[23,24]$ have shed light on the larger-scale processes, covering a period of years. These studies used assessment intervals of 6 months. To answer questions concerning the course of development during a guidance period, we need to have much more dense assessments, at least every week. In one recent study, Klimstra et al. [25] assessed identity on a daily basis, by means of a single-item measurement. In their study, they focused on commitment reconsideration, and they found evidence for day-to-day processes especially in the interpersonal domain of friends and much less in the domain of education. However, as the authors suggest, dayto-day processes will be especially salient in domains in which there is a lot of variation and change possible. During a career guidance, especially the domain of education and career may show a lot of short-term dynamics. In addition, we need longitudinal studies to get insight into the processes after the end at the program. In our study, we interviewed the participants just after the program, without followup. In a future study we plan to follow participants intensively, and for a prolonged period.

Finally, it should be kept in mind that the students with career choice problems in this study are not representative of students with career choice problems in general: the participants were probably highly motivated because participation was voluntary and a fee had to be paid. This does not affect the practical implications, because all intensive career choice programs in The Netherlands are time-consuming and expensive. We know of no reason why the participants in this 
program would differ from participants in other programs. However, only $50 \%$ of the guidance program participants participated in the study so it is not certain that the participants in our study are representative for all participants in the program. Although this is a rather high rate given that participation was completely voluntary and was not rewarded, in future research effort should be spent to increase the participation rate and to get more insight in differences between adolescents who do and do not participate in the study.

Concluding, we found firstly that following the Saxion program the participants showed a significant increase in identity development, and secondly that the students with career choice problems did show relatively immature patterns of identity development. In order to analyze whether and how the program caused this increase we aim in future studies to address commitment and exploration development on a microlevel time scale, to pay attention to qualitative aspects of commitments and exploration, and to include a broader group of students with career choice problems. Moreover, microlevel analysis of individual trajectories is needed to get insight in the type of research questions that are mentioned by [13] concerning individual differences in effectiveness of these interventions.

\section{Appendix}

\section{The Saxion Orientation Program}

The Saxion Orientation Program's main aim is to help the participants to discover what they can and want in the vocational domain. The central theme is "making choices," and at the end of the program participants are expected to be able to make conscious educational and vocational choices, based on insight in their own characteristics, skills, and preferences and on knowledge of contextual affordances. In addition, they are expected to have developed understanding and insight in the process of making choices.

The program lasts for four months and takes two days per week, and it consists of four parts: group meetings, individual sessions, visits to organizations and educational institutions, and homework assignments. In addition it offers the possibility for specific trainings, for example, to learn to cope with fear of failure or with a tendency to postpone, and for additional sessions with career counsellors. Each group consists of about 12 participants and one coach/trainer. The trainers are experienced professionals.

The project consists of two parts. The first period of about 8 weeks is the period of orientation. In this period the focus is on exploring oneself and on exploring the domain of vocational and educational possibilities.

Exercises and meetings stimulate the participants to

(i) develop a realistic perspective on their own skills and characteristics,

(ii) get insight in their ideals, their pitfalls,

(iii) get insight in how they are perceived by others, (iv) get insight in the way they are affected by other people and events,

(v) get knowledge about the domain of education,

(vi) collect information and to learn how to do that.

Techniques that are used are exercises, group meetings in which the participants give and receive feedback from the others and from the coach, and instructions to help them to explore what information is available, to analyze their own past, experiences, preferences, and so forth. The participants learn how to explore the broad domain of education and how to determine whether and how specific types of education fit in with their own wishes and characteristics.

The second phase, of about 12 weeks, is the phase of the confrontation with reality. In this phase the participants explore educations and vocations in detail. The second phase starts with the development of a concrete plan of action. In this phase the participants are coached but are explicitly responsible for their own program. The participants describe what institutions and organizations they intend to visit, the kind of information they want to get from there, what they want to do there, what questions they want to be answered, and so forth. The participants organize interviews and meetings with students and teachers of the educational institutions in which they are interested and visits of and interviews with professionals in the vocational domains in which they are interested. In addition they visit open days, specific classes for aspirant students, meeting days, and other activities that are organized for aspirant students by educational institutions. Also short internships are possible. In addition, the participants orient themselves by reading theses and reports written by students, descriptions of internships, assignments, and so forth. Finally, they gather descriptions of different jobs and studies. The focus not only is on the actual gathering of the information, but also on awareness of the process of gathering information. The participants learn to find, to select, to review critically, and to organize the information they found.

Following this period of confrontation the focus is on the process of making a choice. The participants learn different ways to make choices; they learn to determine which way is best for them at this moment. They learn to analyze who influences their choices. Finally, they make a choice, and are coached to implement this choice by assigning for the studies of their choice, by telling others about their choice, and so forth.

In addition, they are stimulated to reflect on the process of choice making, by means of making reflection reports of their own choice process.

Basic principles in the program are as follows:

focus on the participants' own responsibility, the relevance of lifelong learning,

choices should be made on the basis of actual experience.

Stuit [12] investigated whether the program meets different criteria that are distinguished as relevant in the literature. 
Germeijs and Verschueren [17] have developed a six-step model about the way in which adolescents decide on the first step in their career choice. These different steps describe a process that starts with orientation to choice, self-exploratory behavior, broad exploratory behavior of the environment, indepth exploratory behavior of the environment, decisional status, and commitment. All these six steps are present in the Saxion program.

\section{Acknowledgments}

This paper could be written thanks to the cooperation with the staff of the Saxion Orientatieproject, especially Hendrika Timmerman, Drs. Saskia Vlieger and Astrid Wieferink, and because of the participants in this study.

\section{References}

[1] E. H. Erikson, Identity and the Life Cycle, vol. 1 of Psychological Issues. Monograph 1, International University Press, New York, NY, USA, 1959.

[2] J. E. Marcia, "Development and validation of ego-identity status," Journal of Personality and Social Psychology, vol. 3, no. 5, pp. 551-558, 1966.

[3] H. A. Bosma, Identity development in adolescence. Coping with commitments. [unpublished doctoral disseration], Groningen, The Netherlands, 1985.

[4] A. van Hoof, Identity formation in adolescence: structural integration and guiding influences [unpublished doctoral thesis], University of Utrecht, Utrecht, The Netherlands, 1997.

[5] E. S. Kunnen, V. Sappa, P. L. C. van Geert, and L. Bonica, "The shapes of commitment development in emerging adulthood," Journal of Adult Development, vol. 15, no. 3-4, pp. 113-131, 2008.

[6] E. S. Kunnen, "Are conflicts the motor in identity change?" Identity, vol. 6, no. 2, pp. 169-186, 2006.

[7] H. A. Bosma and E. S. Kunnen, "Determinants and mechanisms in Ego identity development: a review and synthesis," Developmental Review, vol. 21, no. 1, pp. 39-66, 2001.

[8] J. E. Nurmi, "Adolescents' self-direction and self-definition in age-graded sociocultural and interpersonal contexts," in Navigating through Adolescence: European Perspectives, J. E. Nurmi, Ed., Michigan State University Series on Children, Youth and Families, pp. 229-250, Garland Publishing, New York, NY, USA, 2001.

[9] J. J. Arnett, "Emerging adulthood: a theory of development from the late teens through the twenties," American Psychologist, vol. 55, no. 5, pp. 469-480, 2000.

[10] J. J. Arnett, Emerging Adulthood, the Winding Road from the Late Teens through the Twenties, Oxford University Press, New York, NY, USA, 2007.

[11] Trendrapport, Landelijke Jeugdmonitor, (National Report on the Youth), Centraal Bureau voor de Statistiek (Central Office for Statistics), Den Haag, The Netherlands, 2010.

[12] H. Stuit, Assistance in the choice of study, a theoretical study of the potential effectiveness of long-term study choice support programs [M.S. thesis], Groningen, The Netherlands, 2011.

[13] S. D. Brown and N. E. Ryan Krane, "Four (or five) sessions and a cloud of dust: old assumptions and new observations about career counseling," in Handbook of Counseling Psychology, S. D. Brown and R. W. Lent, Eds., pp. 740-766, John Wiley \& son, New York, NY, USA, 2000.
[14] M. J. Montgomery, L. Hernandez, and L. Ferrer-Wreder, "Identity development and intervention studies: the right time for a marriage?" Identity, vol. 8, no. 2, pp. 173-182, 2008.

[15] Saxion Oriëntatieproject: in vier maanden weten wat je wilt, 2011, http://www.saxion.nl/cursus/sop/inleiding.

[16] S. J. Schwartz, W. M. Kurtines, and M. J. Montgomery, "A comparison of two approaches for facilitating identity exploration processes in emerging adults: an exploratory study," Journal of Adolescent Research, vol. 20, no. 3, pp. 309-345, 2005.

[17] V. Germeijs and K. Verschueren, "High school students' career decision-making process: a longitudinal study of one choice," Journal of Vocational Behavior, vol. 68, no. 2, pp. 189-204, 2006.

[18] A. Hirschi and D. Läge, “The relation of secondary students' career-choice readiness to a six-phase model of career decision making," Journal of Career Development, vol. 34, no. 2, pp. 164191, 2007.

[19] R. van Esbroeck, K. Tibos, and M. Zaman, "A dynamic model of career choice development," International Journal for Educational and Vocational Guidance, vol. 5, no. 1, pp. 5-18, 2005.

[20] E. S. Kunnen, “The Groningen Identity Development Scale (GIDS) Norm tables and analyses," 2013, http://www.rug.nl/ staff/e.s.kunnen/gidsnormtablesandanalyses.pdf.

[21] E. S. Kunnen, Internal Report GIDS Analysis, Internal Publication, Department of Developmental Psychology, Groningen, The Netherlands, 2005.

[22] K. Luyckx, S. J. Schwartz, M. D. Berzonsky et al., "Capturing ruminative exploration: extending the four-dimensional model of identity formation in late adolescence," Journal of Research in Personality, vol. 42, no. 1, pp. 58-82, 2008.

[23] K. Luyckx, L. Goossens, and B. Soenens, "A developmental contextual perspective on identity construction in emerging adulthood: change dynamics in commitment formation and commitment evaluation," Developmental Psychology, vol. 42, no. 2, pp. 366-380, 2006.

[24] E. S. Kunnen, "Congruency between domains in commitment development," Identity, vol. 10, no. 4, pp. 254-269, 2010.

[25] T. A. Klimstra, K. Luyckx, W. W. Hale, T. Frijns, P. A. C. van Lier, and W. H. J. Meeus, "Short-term fluctuations in identity: introducing a micro-level approach to identity formation," Journal of Personality and Social Psychology, vol. 99, no. 1, pp. 191-202, 2010. 

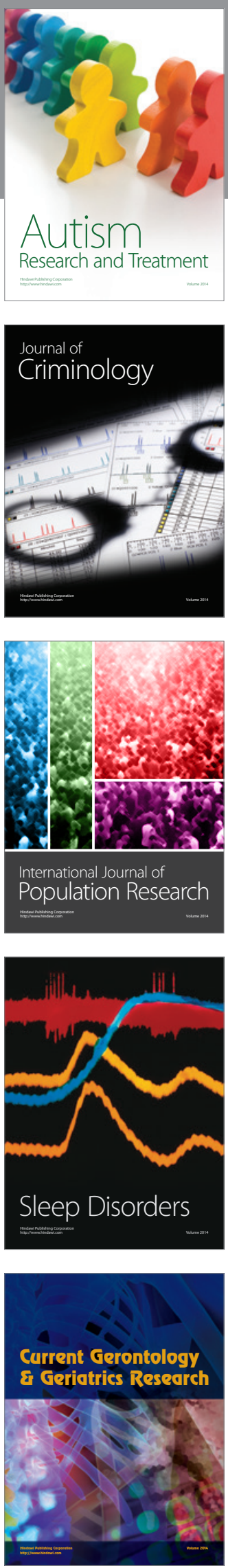
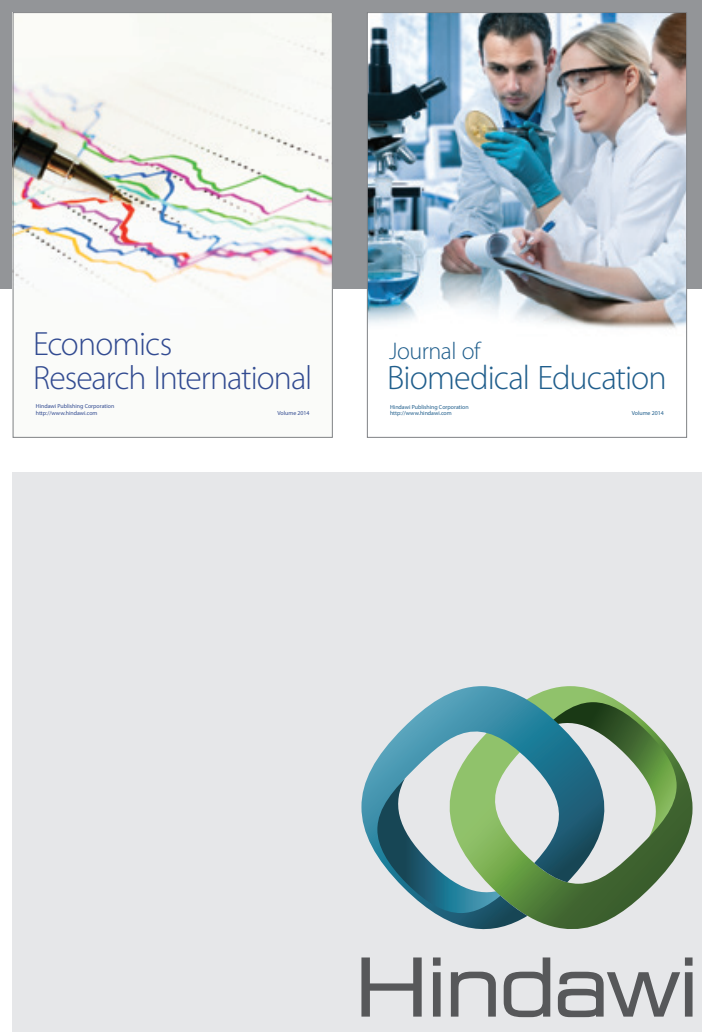

Submit your manuscripts at

http://www.hindawi.com
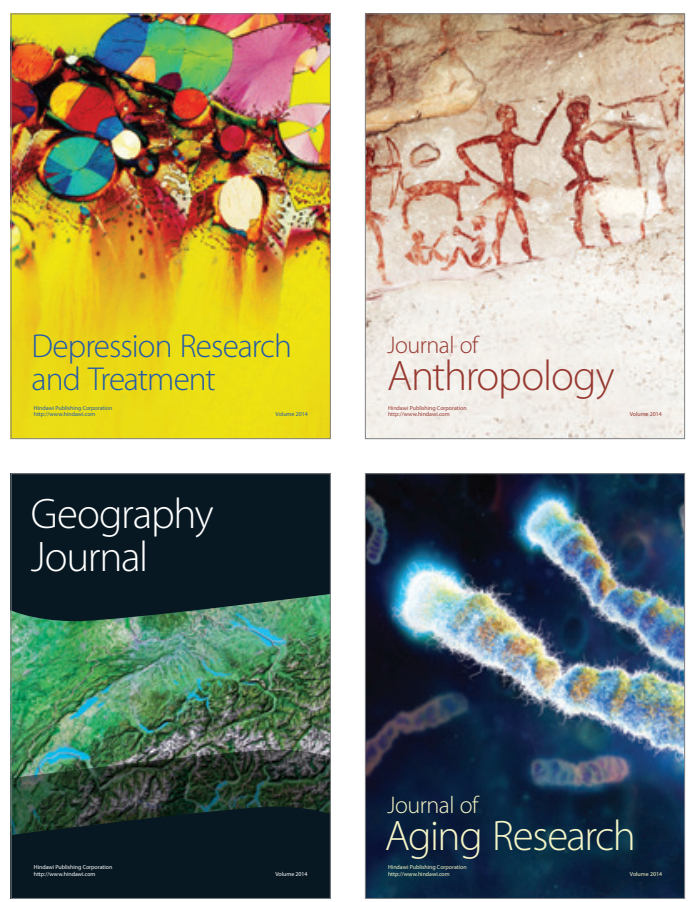
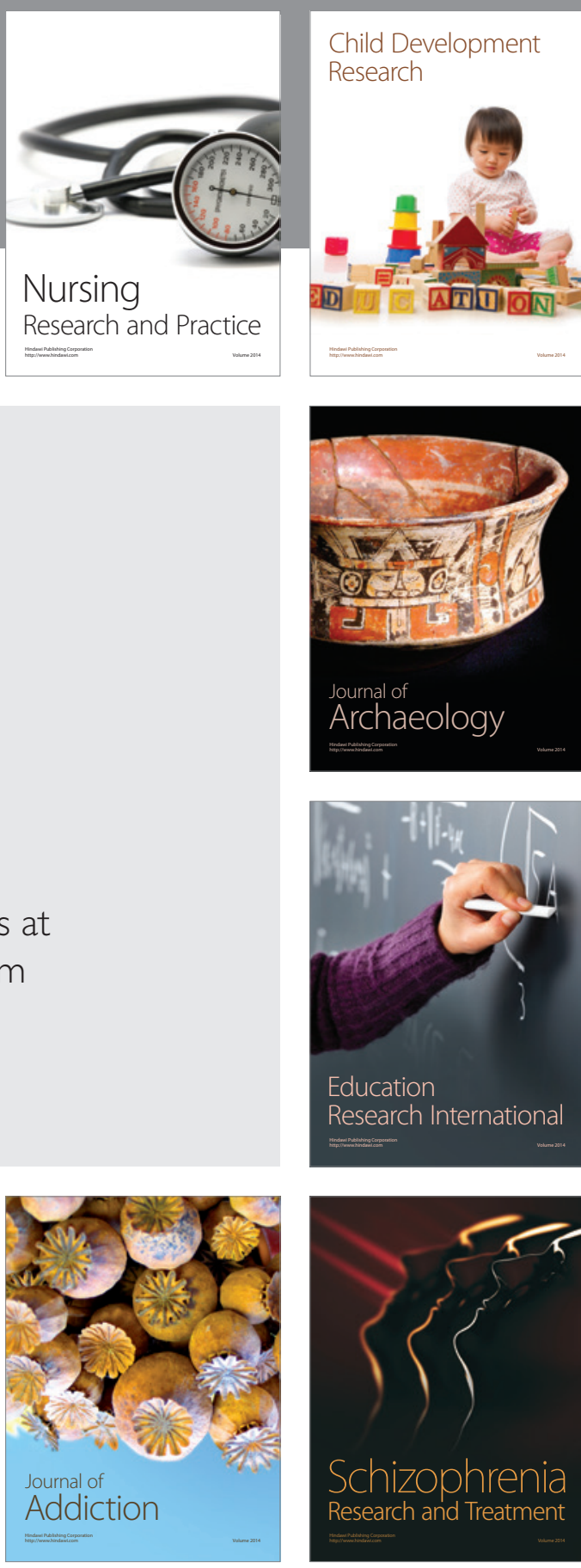

(D)
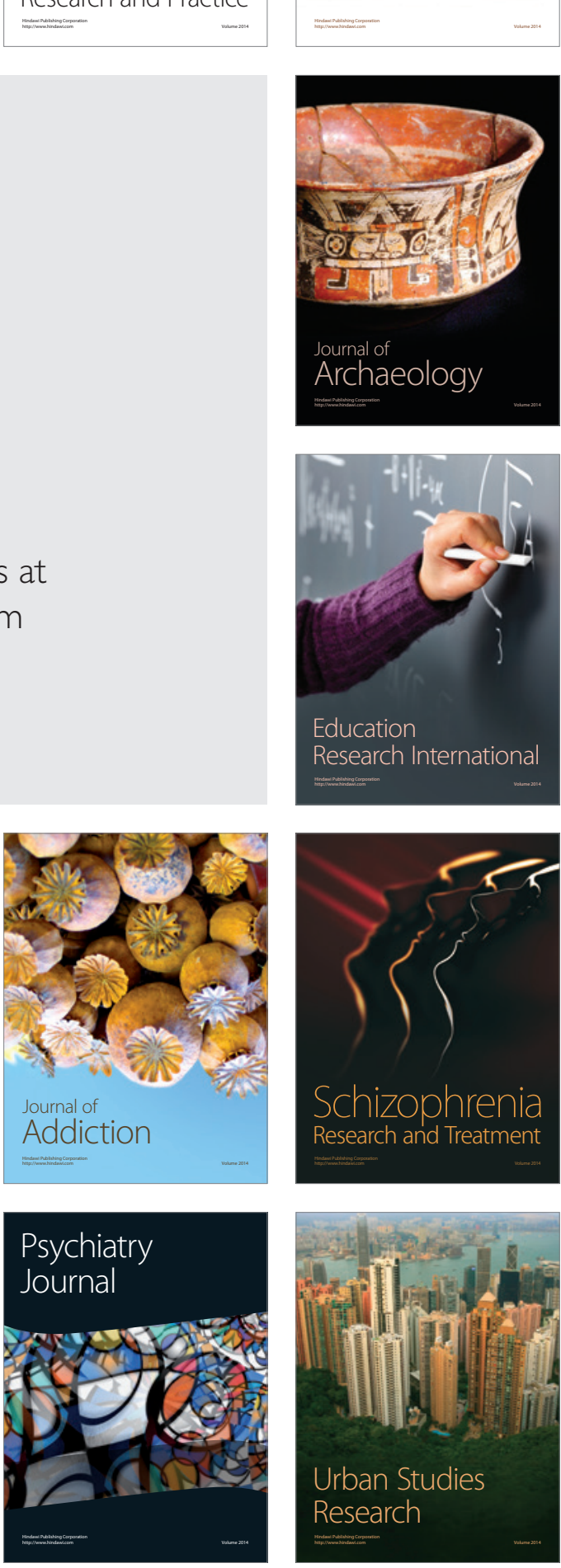